\title{
The influence of thermal treatments on the antioxidant activity and colour of chokeberry (Aronia melanocarpa) extract
}

\author{
Elena CRistea ${ }^{a^{*}}$ \\ a Technical University of Moldova, 168, Stefan cel Mare Blvd, Chisinau MD-2004, Republic of Moldova \\ ${ }^{*}$ Corresponding author \\ cristea.ele@gmail.com \\ TEL: $+447770022884 ;+37322435815$
}

Received: 4 June 2016; Published online: 18 October 2016

\begin{abstract}
Natural ingredients are an important trend in the present day food industry since manufacturers are demanding natural food dyes originating from concentrates of plant origin. However, if the use of plant extracts as technological additives is intended, their stability should be evaluated. This paper presents research on the stability of a $50 \%$ ethanolic extract of chokeberry (Aronia melanocarpa) from the Republic of Moldova. The extract was subjected to various thermal regimes, i.e. $-2{ }^{\circ} \mathrm{C}$ for 12 hours; $4{ }^{\circ} \mathrm{C}$ for 12 hours; $40{ }^{\circ} \mathrm{C}$ for 15 minutes, $60{ }^{\circ} \mathrm{C}$ for 15 minutes, $80{ }^{\circ} \mathrm{C}$ for 15 minutes and $100{ }^{\circ} \mathrm{C}$ for 2 minutes, after which the antioxidant activity and the colour parameters (CIELab) were evaluated. Three sets of extracts were also stored for 2 weeks at $-2{ }^{\circ} \mathrm{C} ; 4^{\circ} \mathrm{C}$; and $25-30{ }^{\circ} \mathrm{C}$ and afterwards the parameters mentioned above were measured once again. Furthermore, total content of polyphenols was determined using the Folin-Ciocalteu method. The antioxidant activity was stable at temperatures under $0{ }^{\circ} \mathrm{C}$ and temperatures as high as $100^{\circ} \mathrm{C}$, as well as during storage at $-2{ }^{\circ} \mathrm{C}, 4{ }^{\circ} \mathrm{C}$ and $25-30{ }^{\circ} \mathrm{C}$. High temperatures however decreased the value of luminosity, and increased the redness, the yellowness and the chroma value which reached a maximum value of 55.66 after the extract was subjected to 100 ${ }^{\circ} \mathrm{C}$ for 2 minutes. Storage at room temperature significantly affected the luminosity of the extract by increasing its value from 42.36 to 50.22 . For most treatments, the colour was stable and was not significantly modified.
\end{abstract}

Keywords: Antioxidant activity; CIELab; Chokeberry extract; Temperature

\section{Introduction}

Natural ingredients are nowadays one of the most significant trends in the food industry since manufacturers are demanding natural food dyes originating from vegetable or fruit concentrates (Hansen, 2015). Berry concentrates are interesting not only because of their colour, but also for their antioxidant activity.

Researchers are coming up with novel approaches by studying natural berry extracts even in foods such as sausages and patties (Burrows, 2015). Many species of berries have been analyzed in the last years for their colour and antioxidant functions. One such species is the chokeberry (Aronia melanocarpa). Cultivated in North America, Eastern Europe and Russia (Bermudez-Soto, Tomas-Barberan, \& Garcia-Conesa, 2007), the genus Aronia (Rosaceae) includes two species of shrubs: Aronia melanocarpa known as black chokeberry and Aronia arbutifolia known as red chokeberry, native to eastern North America and Eastern Canada. Aronia prunifolia (purple chokeberry) is commonly regarded as a hybrid between A. melanocarpa and A. arbutifolia (Wangensteen et al., 2014). 
Many studies have shown that chokeberry juice and extract possess antioxidant, anticarcinogenic, cardioprotective and antidiabetes effects (Savikin et al., 2014; Bermudez-Soto et al., 2007; Kim et al., 2013; Kardum et al., 2014). Skoczynska et al. (2007) found that mildly hypercholesterolemic men who drank $250 \mathrm{~mL}$ of chokeberry juice daily for 6 weeks had $12 \%$ less total cholesterol, $7 \%$ less LDL cholesterol, and 13\% less triglycerides than baseline values.

However, if berry extracts are intended to be used in the future as technological additives in foods, their stability should be evaluated. Food products are subjected to various technological treatments, which may involve high temperatures, high pressure, and microwaves, and the antioxidant properties, as well as the colour, may change after such treatments. Thus, the purpose of this study is to determine the stability of the antioxidant activity and colour parameters of an ethanolic extract of black chokeberry which has undergone different temperature-time regimes. Moreover, the stability at different storage temperatures has been evaluated.

\section{Materials and Methods}

The berries of $A$. melanocarpa were of Moldovan origin. ABTS (2,2'-azino-bis(3ethylbenzothiazoline-6-sulphonic acid) was obtained from Alfa Aesar. Folin-Ciocalteu reagent was purchased from Merck.

\subsection{Preparation of black chokeberry extracts}

Before preparing the extract, the berries were dried at temperatures up to $65{ }^{\circ} \mathrm{C}$, chopped up to the state of a powder and sieved. The extracts were obtained by extraction in $50 \%(\mathrm{v} / \mathrm{v})$ ethanol (1g raw material:10 $\mathrm{mL}$ solvent) solution during $30 \mathrm{~min}$ of continuous stirring at room temperature. The extract was submitted to the following thermal regimes: $-2{ }^{\circ} \mathrm{C}$ for 12 hours; $4{ }^{\circ} \mathrm{C}$ for 12 hours; $40{ }^{\circ} \mathrm{C}$ for 15 minutes, $60{ }^{\circ} \mathrm{C}$ for 15 minutes, $80{ }^{\circ} \mathrm{C}$ for 15 minutes and $100^{\circ} \mathrm{C}$ for 2 minutes. These combinations of time and temperature are more often chosen by food processors to ensure the preservation of foodstuffs.
After the thermal treatments, the antioxidant activity and the colour parameters (CIELab) were measured. Three sets of extracts were kept for 2 weeks at $-2{ }^{\circ} \mathrm{C} ; 4{ }^{\circ} \mathrm{C}$ and $25-30{ }^{\circ} \mathrm{C}$ and afterwards the parameters mentioned above were measured once again. All spectrophotometric measurements were performed using a Specord 200 Plus (Germany) spectrophotometer.

\subsection{Antioxidant activity by reaction with ABTS $^{+\bullet}$ (2,2'-azino-bis $(3$ - ethylbenzothiazoline-6- sulphonic acid) cation radical}

The antioxidant activity of the extracts was assessed by assay with the cation radical $\mathrm{ABTS}^{+}{ }^{\bullet}$ following the method described by Re et al. (1999). The results were expressed as mmol trolox equivalents $(\mathrm{TE} / \mathrm{L})$ from a calibration curve prepared using trolox $(0-2000 \mu \mathrm{mol} / \mathrm{L}$; $\left.\mathrm{R}^{2}=0.9974\right)$.

\subsection{Total polyphenols by Folin-Ciocalteu}

The content of total polyphenols was determined by reaction with Folin-Ciocalteu reagent following the method described by Singleton and Rossi (1965), with some modifications of used quantities of samples and reagents. The results for total polyphenols were calculated from a calibration curve using gallic acid (0-500 mg/L, R $\left.{ }^{2}=0.9988\right)$ and expressed in equivalents of gallic acid $(\mathrm{mg}$ $\left.\mathrm{GAE}^{*} \mathrm{~L}^{-1}\right)$.

\subsection{Colour parameters (CIELab)}

The CIELab parameters were determined using a Specord 200 Plus (Germany) spectrophotometer equipped with a D65 light source and an observation angle of $10^{\circ}$. The calculations were performed using the software WinASPECT PLUS provided by the same company. The transmittance of all the samples was measured in an optical glass cuvette with a path length of $1 \mathrm{~mm}$. Distilled water was used as a reference. 


\subsection{Statistical analysis}

The accuracy was assessed using the methods of mathematical statistics. The mean values and the standard deviations were calculated from 3 parallel experiments. ANOVA and post-hoc Tukey test were used to distinguish between means and evaluate the results. The level of significance was set at $95 \%$ and the results were considered significantly different when $p \leq 0.05$. The calculations were performed using IBM SPSS Statistics 23.

\section{Results and Discussion}

\subsection{The influence of temperature on the antioxidant activity and colour parameters of chokeberry extract}

The total polyphenol content measured in the ethanolic chokeberry extract was $5553 \pm 201 \mathrm{mg}$ $\mathrm{GAE}^{*} \mathrm{~L}^{-1}$, while the measured value of the antioxidant activity was $36.18 \pm 1.12 \mathrm{mmol} \mathrm{TE} \mathrm{TL}^{-1}$. The initial values of colour parameters can be found in the first lines of Tables 1 and 2 .

Other authors have also found high amounts of polyphenols in fresh berries of Aronia melanocarpa, e.g. Wangensteen et al. (2014) found 1079-1921 (depending on the cultivar) $\mathrm{mg} / 100 \mathrm{~g}$ fresh product in berries of Aronia melanocarpa from Norway, of which 275-447 $\mathrm{mg} / 100 \mathrm{~g}$ fresh product were anthocyanins. The results obtained by the aforementioned authors are different from the ones obtained in the present study, however, the fact that fresh products were assessed by other authors must be taken into account. Tolic, Jurcevic, Krbavcic, Markovic, and Vahcic (2015) evaluated different products made from chokeberry from Croatia in terms of their polyphenol content and antioxidant activity. The authors found that chokeberry products (juices, powders, and teas) contain high amounts of polyphenols (3002 to $6639 \mathrm{mg}^{*} \mathrm{~L}^{-1}$ and 1494 to $5292 \mathrm{mg} / 100 \mathrm{~g}$ of dry matter) and high antioxidant capacities (2.09 to $40.19 \mathrm{mmol}^{*} \mathrm{~L}^{-1}$ or 58.49 to $191.31 \mathrm{mmol} / 100 \mathrm{~g}$ of dry matter). Their results are similar to the ones obtained in this study. The authors suggest that these results place the chokeberries among the fruits with the highest polyphenol content. The high content of polyphenols, specifically anthocyanins, contribute to the colour and the antioxidant activity of the extract. A comparatively low luminosity $\left(\mathrm{L}^{*}\right)$ was found, i.e. 42.36 . Red and yellow pigments are the main pigments which affect the colour quality of the extract. Similar results for colour parameters were also reported by Tolic et al. (2015).

The results from Figure 1 show the modification of the antioxidant activity after thermal treatments at different temperatures. No statistically significant variation of the antioxidant activity was observed between the fresh extract and those subjected to all thermal treatments, thus the ethanolic extract of Aronia melanocarpa is stable when submitted to both temperatures under $0^{\circ} \mathrm{C}$ and higher temperatures used in food processing. However, there were significant differences between the thermal treatment carried out at 100 ${ }^{\circ} \mathrm{C}$ for $2 \mathrm{~min}$ and those at $-2{ }^{\circ} \mathrm{C}$ for 12 hours; $40{ }^{\circ} \mathrm{C}$ for $15 \mathrm{~min}$; and $60{ }^{\circ} \mathrm{C}$ for $15 \mathrm{~min}$. Several other studies have also demonstrated that polyphenols are stable to the action of temperature (Kurzeja, Stec, Ramos, Pilawa, \& Pawlowska-Goral, 2012; Jeong et al., 2004). However, it has also been reported that pasteurisation and storage, particularly when oxygen is available, can affect antioxidant activity in a negative way (WalkowiakTomczak, 2007).

Table 1 summarizes the values obtained for $\mathrm{L}^{*}$, $\mathrm{a}^{*}, \mathrm{~b}^{*}, \mathrm{C}^{*}$ and $\mathrm{H}^{*}$ for the different technological treatments. High temperatures displayed a significant effect on all colour parameters, by decreasing the value of luminosity and therefore making the extract darker. On the other hand, the redness and yellowness of the extract increased. The chroma value also increased with the temperature, with the highest value of 55.66 found after the extract underwent treatment at $100^{\circ} \mathrm{C}$ for 2 minutes.

\subsection{The influence of storage conditions on the antioxidant activity and colour parameters}

Three sets of extracts were also stored for two weeks and their antioxidant activities and colour 


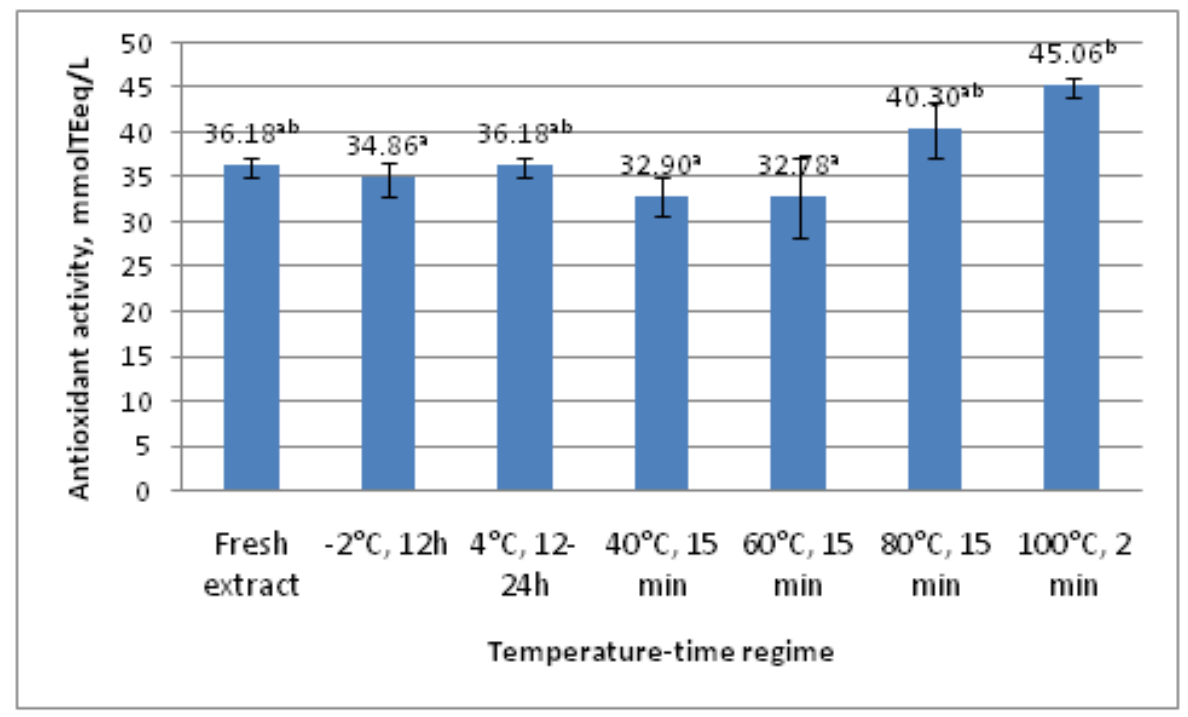

Figure 1: The influence of temperature-time regime on the antioxidant activity of chokeberry ethanolic extract (the results are expressed as means \pm standard deviations, different letters designate significantly different results)

Table 1: The change of colour parameters during various thermal treatments (the results are expressed as means \pm standard deviations, different letters designate significantly different results)

\begin{tabular}{llllll}
\hline Temperature-time regime & $L^{*}$ & $a^{*}$ & $b^{*}$ & $C^{*}$ & $H^{*}$ \\
\hline Fresh extract, room temperature & $42.36 \pm 0.13^{b}$ & $41.79 \pm 0.07^{a}$ & $24.90 \pm 0.04^{b}$ & $48.65 \pm 0.09^{a}$ & $1.47 \pm 0.01^{c}$ \\
$-2^{\circ} \mathrm{C}, 12 \mathrm{~h}$ & $44.66 \pm 0.03^{d}$ & $42.36 \pm 0.03^{a}$ & $22.87 \pm 0.06^{a}$ & $48.13 \pm 0.06^{a}$ & $1.67 \pm 0.01^{e}$ \\
$4^{\circ} \mathrm{C}, 12-24 \mathrm{~h}$ & $42.33 \pm 0.12^{b}$ & $41.81 \pm 0.07^{b, c}$ & $24.90 \pm 0.05^{c}$ & $48.66 \pm 0.08^{a}$ & $1.48 \pm 0.01^{c}$ \\
$40^{\circ} \mathrm{C}, 15 \mathrm{~min}$ & $43.90 \pm 0.04^{c}$ & $42.47 \pm 0.36^{c}$ & $22.93 \pm 0.07^{a}$ & $48.26 \pm 0.35^{a}$ & $1.67 \pm 0.01^{e}$ \\
$60^{\circ} \mathrm{C}, 15 \mathrm{~min}$ & $44.48 \pm 0.39^{c, d}$ & $42.39 \pm 0.20^{c}$ & $24.32 \pm 0.16^{b}$ & $48.87 \pm 0.26^{a}$ & $1.55 \pm 0.01^{d}$ \\
$80^{\circ} \mathrm{C}, 15 \mathrm{~min}$ & $42.55 \pm 0.22^{b}$ & $43.38 \pm 0.22^{d}$ & $27.02 \pm 0.05^{c}$ & $51.11 \pm 0.18^{b}$ & $1.39 \pm 0.01^{b}$ \\
$100^{\circ} \mathrm{C}, 2 \mathrm{~min}$ & $29.67 \pm 0.33^{a}$ & $45.31 \pm 0.62^{e}$ & $32.33 \pm 0.48^{e}$ & $55.66 \pm 0.78^{c}$ & $1.16 \pm 0.01^{a}$ \\
\hline
\end{tabular}

Table 2: The change of colour parameters at various storage conditions (the results are expressed as means \pm standard deviations, different letters designate significantly different results)

\begin{tabular}{llllll}
\hline Temperature-time regime & $L^{*}$ & $a^{*}$ & $b^{*}$ & $C^{*}$ & $H^{*}$ \\
\hline Fresh extract, room temperature & $42.36 \pm 0.13^{a}$ & $41.79 \pm 0.07^{a}$ & $24.90 \pm 0.04^{a}$ & $48.65 \pm 0.09^{a}$ & $1.47 \pm 0.01^{c}$ \\
$-2^{\circ} \mathrm{C}$, 2 weeks & $46.13 \pm 0.20^{b}$ & $41.28 \pm 0.12^{b, c}$ & $25.00 \pm 0.07^{a}$ & $48.26 \pm 0.13^{a}$ & $1.44 \pm 0.01^{b}$ \\
$4^{\circ} \mathrm{C}, 2$ weeks & $42.61 \pm 0.43^{a}$ & $41.68 \pm 0.22^{b, c}$ & $27.83 \pm 0.09^{b}$ & $48.65 \pm 0.09^{a}$ & $1.47 \pm 0.01^{c}$ \\
$25-30^{\circ} \mathrm{C}, 2$ weeks & $50.22 \pm 0.06^{c}$ & $38.37 \pm 0.12^{a}$ & $36.52 \pm 0.20^{c}$ & $52.97 \pm 0.23^{b}$ & $0.71 \pm 0.01^{a}$ \\
\hline
\end{tabular}




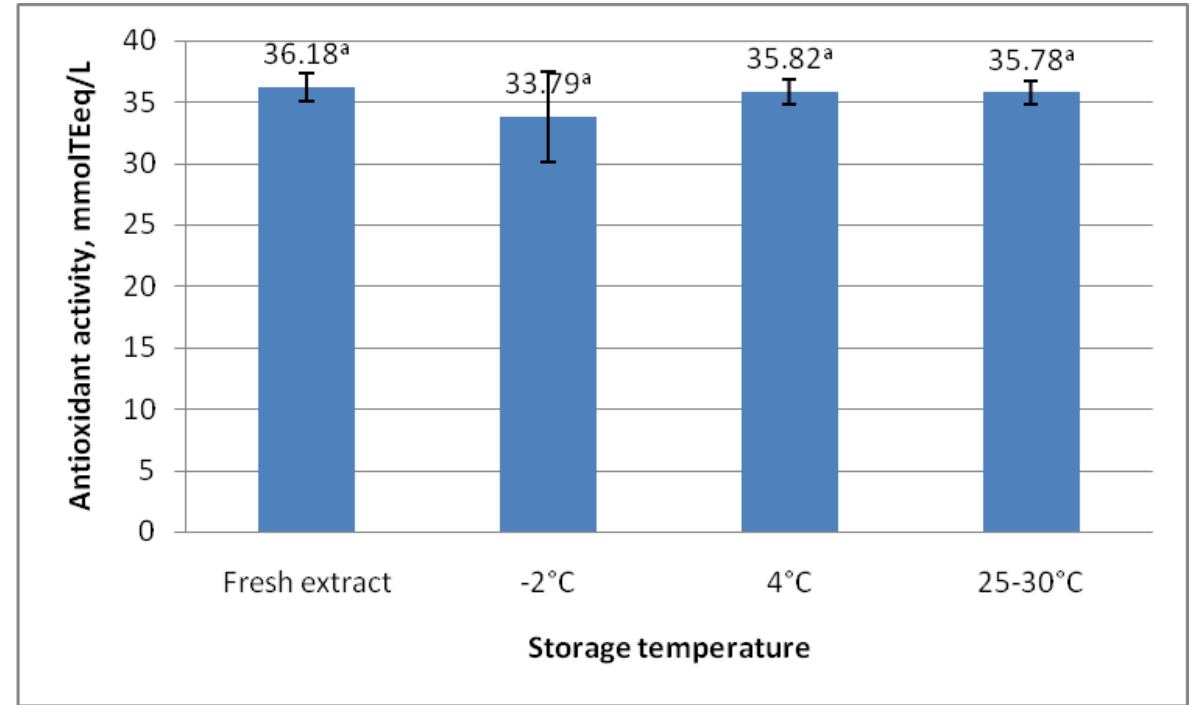

Figure 2: The influence of temperature on the antioxidant activity of chokeberry ethanolic extract during storage (the results are expressed as means \pm standard deviations, different letters designate significantly different results)

Table 3: Overall colour difference between the fresh extract and extracts subjected to various thermal treatments

\begin{tabular}{ll}
\hline Time-temperature regime & $\begin{array}{l}\Delta E^{*} \text { between the fresh extract and } \\
\text { extract subjected to respective regime }\end{array}$ \\
\hline$-2^{\circ} \mathrm{C}, 12 \mathrm{~h}$ & 3.12 \\
$4^{\circ} \mathrm{C}, 12-24 \mathrm{~h}$ & 0.04 \\
$40^{\circ} \mathrm{C}, 15 \mathrm{~min}$ & 2.59 \\
$60^{\circ} \mathrm{C}, 15 \mathrm{~min}$ & 2.27 \\
$80^{\circ} \mathrm{C}, 15 \mathrm{~min}$ & 2.66 \\
$100^{\circ} \mathrm{C}, 2 \mathrm{~min}$ & 15.12 \\
$-2^{\circ} \mathrm{C}, 2$ weeks & 3.81 \\
$4^{\circ} \mathrm{C}, 2$ weeks & 2.94 \\
$25-30^{\circ} \mathrm{C}, 2$ weeks & 14.44 \\
\hline
\end{tabular}


parameters were monitored. Figure 2 shows the results for the antioxidant activity after two weeks of storage at $-2{ }^{\circ} \mathrm{C}, 4{ }^{\circ} \mathrm{C}$ and $25-30{ }^{\circ} \mathrm{C}$. No significant differences were found for this parameter, which suggests that storage temperatures can vary from under $0{ }^{\circ} \mathrm{C}$ up to room temperature, for the preservation of the antioxidant activity.

The results for colour parameters, measured in the stored extracts, are presented in Table 2. The results for the $L^{*}$ parameter show that the most significant effect on the luminosity of the extract was exerted by storage at $-2{ }^{\circ} \mathrm{C}$ and 25 $30{ }^{\circ} \mathrm{C}$, whereby increasing its value from 42.36 to 46.13 and 50.22 , respectively, and resulting in a lighter extract. Furthermore, storage at 25$30^{\circ} \mathrm{C}$ increased $b^{*}$ which can be interpreted as a more yellow extract, decreased $a^{*}$ which is interpreted as less red and decreased the hue angle. The increase of the blue/yellow parameter can be attributed to the formation of pyroanthocyanins (Torchio, Segade, Gerbi, Cagnasso, \& Rolle, 2011). However, all these modifications produced a higher value for chroma, interpreted as an enhanced colour quality.

Table 3 presents the overall difference in colour between the freshly prepared extract and those exposed to different thermal regimes and storage temperatures. For most treatments, except the ones involving temperatures of $80{ }^{\circ} \mathrm{C}$ and $100{ }^{\circ} \mathrm{C}$, the colour was stable and was not modified significantly since the reported perceptibility threshold for CIELab colorimetric differences are $\Delta \mathrm{E}^{*}=0.8-1$ (Gonnet, 2001) and $\Delta \mathrm{E}^{*}=3$ (Martinez, Melgosa, Perez, Hita, \& Negueruela, 2001). Higher $\Delta \mathrm{E}^{*}$ values were obtained for the extract exposed to $100^{\circ} \mathrm{C}$ for $2 \mathrm{~min}$ and the one kept at $25-30^{\circ} \mathrm{C}$ for two weeks, i.e. 15.12 and 14.44 , respectively. These values suggest there might be perceptible changes of colour during processing involving temperatures $\geq 80{ }^{\circ} \mathrm{C}$ and storage at room temperature, in the presence of light. However, it must be taken into account that the reported perceptibility threshold is for wines and a sensory analysis is necessary before reaching a final conclusion.

\section{Conclusions}

High amounts of total polyphenols (5553 mgGAE* $\mathrm{L}^{-1}$ ) were detected in an ethanolic chokeberry extract which contributed to its high antioxidant activity $\left(36.18 \mathrm{mmol} \mathrm{TE}^{*} \mathrm{~L}^{-1}\right)$ and deep red colour. Furthermore, the antioxidant activity was stable at temperatures under $0^{\circ} \mathrm{C}$ and temperatures as high as $100^{\circ} \mathrm{C}$, as well as during storage at $-2^{\circ} \mathrm{C}, 4^{\circ} \mathrm{C}$ and $25-30^{\circ} \mathrm{C}$. High temperatures, however, had a significant effect on all colour parameters by decreasing the value of luminosity, increasing the redness, the yellowness and the chroma value which reached 55.66 after the extract was subjected to $100^{\circ} \mathrm{C}$ for 2 minutes. On the other hand, storage at room temperature affected the luminosity of the extract by increasing its value from 42.36 to 50.22 , and resulting in a lighter extract. For most treatments the colour was stable and was not modified which indicates that chokeberry extract could be used as a dye in foods which are submitted to thermal treatments. Overall, colour difference values superior to the perceptibility threshold were obtained only for the extract which underwent treatment at $100^{\circ} \mathrm{C}$ for $2 \mathrm{~min}$ and the one kept at $25-30^{\circ} \mathrm{C}$ for two weeks, i.e. 15.12 and 14.44 , respectively. Therefore, special care should be taken when chokeberry ethanolic extract is submitted to processing involving high temperatures since it might produce perceptible changes in colour. Furthermore, storage at room temperatures, in presence of light should be avoided for the same reason.

\section{Acknowledgements}

Elena Cristea is recipient of Eugen Ionescu scholarship offered by Agence Universitaire de la Francophonie and the Ministry of Foreign Affairs of Romania. The author would like to thank the project AUF BECO-2012-53-U-56135FT205 and the professors Rodica Sturza and Antoanela Patras for their guidance and help. 


\section{References}

Bermudez-Soto, M. J., Tomas-Barberan, F. A., \& Garcia-Conesa, M. T. (2007). Stability of polyphenols in chokeberry (aronia melanocarpa) subjected to in vitro gastric and pancreatic digestion. Food Chemistry, 102(3), 865-874. doi:10.1016/j.foodchem. 2006.06 .025

Burrows, D. (2015). Can "healthier" sausages fortified with berry antioxidants reduce cancer risk? Retrieved from http : / / www . foodnavigator . com / Science / Can - healthier - sausages - fortified - with berry - antioxidants - reduce - cancer - risk? sf $15755350=1$

Gonnet, J. F. (2001). Colour effects of copigmentation of anthocyanin revisited - 3. a further description using cielab differences and assessment of matched colours using the cmc model. Food Chemistry, 75(4), 473-485. doi:10 . 1016 / S0308 - 8146(01) 00221-7

Hansen, C. (2015). Advancing nature's brilliance together - chr. hansen natural colors profile brochure. london. Retrieved from http:// snowballcopy. com / wp - content / uploads / 2015/09 / Chr_Hansen_297x210_mm_broch_ final_5.pdf

Jeong, S. M., Kim, S. Y., Kim, D. R., Jo, S. C., Nam, K. C., Ahn, D. U., \& Lee, S. C. (2004). Effect of heat treatment on the antioxidant activity of extracts from citrus peels. Journal of Agricultural and Food Chemistry, 52(11), 3389-3393. doi:10. 1021/jf049899k

Kardum, N., Takic, M., Savikin, K., Zec, M., Zdunic, G., Spasic, S., \& Konic-Ristic, A. (2014). Effects of polyphenol-rich chokeberry juice on cellular antioxidant enzymes and membrane lipid status in healthy women. Journal of Functional Foods, 9, 8997. doi:10.1016/j.jff.2014.04.019

Kim, B., Ku, C. S., Pham, T. X., Park, Y., Martin, D. A., Xie, L., ... Bolling, B. W. (2013). Aronia melanocarpa (chokeberry) polyphenol-rich extract improves antioxidant function and reduces total plasma cholesterol in apolipoprotein e knockout mice. Nutrition Research, 33(5), 406-413. doi:10.1016/j.nutres.2013.03.001

Kurzeja, E., Stec, M., Ramos, P., Pilawa, B., \& Pawlowska-Goral, K. (2012). The influence of sterilization on fre-radical generation, discoloration and the antioxidant properties of certain spice herbs. Italian Journal of Food Science, 24(3), 254-262.

Martinez, J. A., Melgosa, M., Perez, M. M., Hita, E., \& Negueruela, A. I. (2001). Note. visual and instrumental color evaluation in red wines. Food Science and Technology International, 7(5), 439-444. doi:10.1106/ VFAT-5REN-1WK2-5JGQ

Re, R., Pellegrini, N., Proteggente, A., Pannala, A., Yang, M., \& Rice-Evans, C. (1999). Antioxidant activity applying an improved abts radical cation decolorization assay. Free Radical Biology and Medicine, 26(9-10), 1231-1237. doi:10 .1016 / S08915849(98)00315-3

Savikin, K., Zdunic, G., Jankovic, T., Godevac, D., Stanojkovic, T., \& Pljevljakusic, D. (2014). Berry fruit teas: phenolic composition and cytotoxic activity. Food Research International, 62, 677-683. doi:10.1016/j. foodres.2014.04.017

Singleton, V. L. \& Rossi, J. A. (1965). Colorimetry of total phenolics with phosphomolybdic-phosphotungstic acid reagents. American journal of Enology and Viticulture, 16(3), 144-158.

Skoczynska, A., Jedrychowska, I., Poreba, R., Affelska-Jercha, A., Turczyn, B., Wojakowska, A., \& Andrzejak, R. (2007). Influence of chokeberry juice on arterial blood pressure and lipid parameters in men with mild hypercholesterolemia. Pharmacological Reports, 59(1), 177-182.

Tolic, M.-T., Jurcevic, I. L., Krbavcic, I. P., Markovic, K., \& Vahcic, N. (2015). Phenolic content, antioxidant capacity and quality of chokeberry (aronia inelanocarpa) products. Food Technology and Biotechnology, 53(2), 171-179.

Torchio, F., Segade, S. R., Gerbi, V., Cagnasso, E., \& Rolle, L. (2011). Changes in chromatic characteristics and phenolic composition during winemaking and shelf-life of two types of red sweet sparkling wines. 
Influence of temperature on the antioxidant activity of chokeberry extract $\mid 231$

Food Research International, 44(3), 729738. doi:10.1016/j.foodres.2011.01.024

Walkowiak-Tomczak, D. (2007). Changes in antioxidant activity of black chokeberry juice concentrate solutions during storage. Acta Scientiarum Polonorum Technologia Alimentaria, 6(2), 49-54.

Wangensteen, H., Braunlich, M., Nikolic, V., Malterud, K. E., Slimestad, R., \& Barsett, H. (2014). Anthocyanins, proanthocyanidins and total phenolics in four cultivars of aronia: antioxidant and enzyme inhibitory effects. Journal of Functional Foods, 7, 746-752. doi:10.1016/j.jff.2014.02.006 